JAN ČERNÝ ${ }^{1}$

E-mail: cerny@fm.vse.cz

ŠTEFAN PEŠKO ${ }^{2}$

(Corresponding author)

E-mail: pesko@frcatel.fri.uniza.sk

ANNA ČERNÁ ${ }^{1}$

(Corresponding author)

E-mail: cerna@fm.vse.cz

${ }^{1}$ Faculty of Management

University of Economics in Prague

Jarošovská 1117/II, 37701 Jindřichův Hradec,

Czech Republic

2 Faculty of Management Science and Informatics

University of Žilina

Univerzitná 8215/1, 01026 Žilina, Slovakia
Traffic Planning

Preliminary Communication

Submitted: 4 Dec. 2017

Accepted: 4 Apr. 2019

\title{
ALTERNATE CRITERIA IN LP SOLUTIONS OF PUBLIC TRANSPORT LINE PLANNING
}

\begin{abstract}
In the paper, the public transportation line planning means planning of routes and frequencies of vehicles on them. In the world literature, different criteria are used in this context; mainly the variable costs of lines, the fixed costs of lines, the fixed plus variable costs of lines, the number of direct travellers, the total or average riding time and the total or average travelling time. The current paper adds two more: the total number of used vehicles (to be minimized when all passengers are transported) and relative excess of supply over demand (to be maximized without exceeding the number of available vehicles). Basic mathematical models for both cases are presented and the motivation of such approach is described including a brief excursion into the history of the Czech and Slovak research of line planning where the use of these objectives has arisen. Further, the basic models were modified for the cases of fourteen special practical requirements, e.g. heterogeneous vehicle fleet (= rolling stock), limitation of transfers, elastic demand, limited total number of lines, etc. The brief outline of the experience with practical use is added as well.
\end{abstract}

\section{KEY WORDS}

public transportation; line planning; linear programming; criterion; objective function;

\section{INTRODUCTION}

The current paper deals with the public transport line design, i.e. the design of routes and frequencies of vehicles on them. This issue belongs to the general theory of public transport planning presented in books like [1], extensive book sections as [2] or large survey-type papers such as [3] or [4]. The structure of this planning process and the line planning position in it are described in more detail later in this Section.

Line planning has been discussed in hundreds of publications over the past decades, as seen from survey papers [5, 6, 7]. However, the PRIVOL method, successfully used in the Czech and Slovak Republics, is not mentioned there. The main purpose of this paper is to explain to the readers its essence and to demonstrate its ability to work with Mixed Integer Linear Programming (MILP) models to address many specific transport situations. PRIVOL is based on the so-called Erlander approach, which is explained later in this Section. PRIVOL is actually a linear modification, avoiding the passenger time loss criterion (used by Erlander), which is non-linearly linked to the number of vehicles deployed, as presented later in this Section.

Further, two basic problems P1 and P2 have been formulated, to which the method PRIVOL has been originally designed.

Section 2 lists 14 requirements of public transport engineers for specific conditions, which should be added to the method PRIVOL so that solutions using MILP models would continue to be possible.

Sections 3 and 4 show that all requirements can be formulated in the linear form and solved by LP (= linear programming) which proves the truth of the basic hypothesis.

Section 5 is focused on the discussion and remarks to previous Sections.

Final Section 6 presents conclusions of the paper and outlines the possibilities of future research.

The method PRIVOL, problems P1 \& P2 with all 14 modifications and the MILP models for their solution are original research results of the authors' team.

\section{Public transport planning steps}

In general, the planning process starts when a candidate network, available fleet (= rolling stock) of vehicles and passenger demand (usually in the form of an O-D matrix) are given. The process consists of the following steps: 
1) Choice of subnetwork for public transport operation and, if necessary, rebuilding sections of a candidate network that are not yet eligible for public transport.

2) Design of routes (briefly "routing").

3) Determining of frequencies (briefly "frequencing”).

4) Timetabling.

5) Vehicle scheduling.

6) Crew scheduling.

7) Crew rostering.

Two consecutive steps of this process sometimes merge into one step, for example the fifth with the sixth, the sixth with the seventh, or the second with the third. And just the last one, i.e. combining routing and frequencing into one step is the topic the current paper deals with. The result of this procedure is a set of public transport lines. Here, each line is defined by two important data: the route and the frequency of vehicles, i.e. the results of the $2^{\text {nd }}$ and $3^{\text {rd }}$ steps.

In the current paper, it is supposed that the public transportation operates on a network represented by a (undirected) graph $G=(V, E)$ where the set of vertices (= nodes) $V$ represent potential stops/stations of vehicles (i.e. buses, trolleybuses, trams, trains, etc.) and the set of edges $E$ represent network segments enabling direct movement of vehicles between stops (not passing any other stop). The goal is to find a set of public transport lines that will operate on network $G$.

A public transportation line $l$ is usually defined by two basic data:

- Route $r_{l}=v_{l 0}, v_{l 1}, \ldots, v_{l, m(l)}$, where $m(l)$ means the number of inter-stopping edges, $v_{l 0}$ and $v_{l, m}(l)$ are the terminals (with $v_{l 0}=v_{l, m(l)}$ for a circular line), $v_{l 1}, \ldots, v_{l, m}(l)-1$ are the intermediate stops, listed in the order in which they are passed.

- Timetable $T_{l}$ describing the movement of all services in both directions of route $r_{l}$. For the purposes of the current paper, it is strongly simplified and specified later, together with individual models.

Symbol $E_{l}$ expresses all edges passed by the route $r_{l}$, i.e. that are equal to at least one inter-stopping edge of $r_{l}$.

Line planning is one of the most important activities of urban transport managers. It determines both the carriers' costs and the passengers' satisfaction.

\section{Erlander approach to line planning}

It is not surprising that line planning has been an intensely studied issue, especially in the last four decades. Perhaps, even more than some hundreds papers have been focused on this topic. Survey type papers, like [5, 6, 7] have a prominent position among them. The last two are quite recent (2009/2012) and one can find much more than a hundred entries in their bibliography. Therefore, the bibliography of the current paper does not contain the items cited there. However, there is one exception. Since paper [8] represents the inspiration for creating the method PRIVOL that is mentioned in the following Sections, it enters the bibliography although it is cited in [5].

In 1976, S. Erlander gave lectures in Prague and Žilina where he widely explained the results of [8], mainly the original approach to the combination of routing and frequencing in one step. Since that time, the Czech and Slovak researchers have named it 'Erlander approach' or 'Erlander principle'. It deals with the given set of potential lines $L_{0}$ (= candidate routes in [6]) and the goal is to choose a subset $L \subset L_{0}$ by means of a selective variable $x_{l} \in\{0,1,2, \ldots\}$ defined for all $l \in L_{0}$ and having the following meaning: $x_{l}=0 \Rightarrow l \notin L$ i.e. the candidate line $l$ is not selected and $x_{l}>0 \Rightarrow l \in L$ i.e., $l$ is selected into $L$. Therefore, the selected subset is $L=\left\{l \in L_{0}: x_{l}>0\right\}$. First, $x_{l}$ expressed the number of vehicles assigned to $l$, but later, in the Czech and Slovak (briefly CS) situation, it was shown that similar role may be fulfilled by $x_{l}$ expressing frequency, i.e. the number of services per hour or the static or dynamic capacity of vehicles assigned to I [9].

S. Erlander [8] used this approach together with the objective expressing the total time losses of passengers. This led to the need to use non-linear programming model, since loss of time while waiting for the connection is inversely proportional to frequency. Moreover, the model had to be protected against value $x_{l}=0$ in the denominator. These complications caused that, in the early eighties, CS available computers were able to handle sets $L_{0}$ of maximal cardinality 15 , although the practical needs were at least 10 times greater. Therefore, for a CS use of Erlander approach, it was necessary to abandon the time loss objective and to look for another one, enabling the use of linear programming on one side, but keeping in mind the time loss of passengers on the other side.

\section{Erlander approach combined with linear programming}

In the eighties, CS researchers sought an objective function that would be linearly dependent on variables $x_{l}$. The model they started with, included the following assumptions:

- all vehicles have the same capacity $c$ (i.e. the number of places for passengers) and the number of available vehicles is $n$;

- for all $l \in L_{0}$, the cycle time is $t$, (= the round trip running time plus layover time at each end of the line $l$ ), and

- all passengers mentioned in OD-matrix have to be transported.

To meet the last assumption, some of the traffic assignment methods were used to calculate the traffic load $f_{e}$ for each $e \in E$, i.e. the larger of the numbers of passengers travelling along edge $\mathrm{e}$ in both directions (within one hour). 
When variables $x_{l}$ meant the number of assigned buses (or other types of vehicles like trolleybuses or trams, for instance) then the Erlander's constraint [8] was

$$
\sum_{l \in L_{0}} x_{l} \leq n
$$

expressing the limited number of available vehicles and the "new" constraint was

$\sum_{l \in L 0: e \in E l} \frac{60 c}{t_{l}} x_{l} \geq f_{e}$ for each $e \in E$

requiring sufficient supply of places for passengers on each section of the network, since $60 x_{l} / t_{l}$ is the frequency of line $l$ and $c$ is the capacity of the unique vehicle in the system.

\section{Problem P1: Number of vehicles as the objective}

The first idea (see [9] and [10]) concerning the objective function was to take the total number of used vehicles

$z_{1}=\sum_{l \in L 0} x_{l}$

The reasoning was that if all passengers are transported by a minimal number of vehicles, then their total riding time can be expected to be minimal as well.

Problem P1 was to find integer variables $x_{l} \geq 0$ for $l \in L_{0}$ meeting the Constraints 1 and 2 and minimizing the Objective function 3. Using available computers at that time it was possible to solve instances of P1 with about 100 elements in set $L_{0}$ and with networks that had about 100 edges.

However, several managers of public administration were not fully satisfied with the reached results. Their main problem was not the lack of vehicles, but the lack of comfort for passengers who often had to stand (when all the seats were occupied) in the vehicles for tens of minutes. Therefore, the researchers looked for another linear objective function - the minimal (relative) reserve of places for passengers - to be maximized.

Problem P2: Maximum of minimal reserve of places for passengers

It was obvious that the reserve of places for passengers had to be maximized everywhere, on each edge of the network. Consequently, there was no sense in looking for some objective of summation type but rather of the Max-Min one [9].

Constraint 1 remained unchanged. Constraint 2 was modified into the form

$$
\sum_{l \in L 0: e \in E l} \frac{60 c}{t_{l}} x_{l} \geq y f_{e} \text { for each } e \in E
$$

where $y \in\langle 0, \infty)$ is an auxiliary variable, representing the minimal relative excess of supply over demand. Finally, the objective is

$$
y \rightarrow \max
$$

i.e. the smallest relative excess (with respect to $e \in E$ ) ought to be maximal. Conditions 1, 4 and 5 form problem P2.

The solution method for both problems P1 and P2 and the corresponding PC program were called PRIVOL (Slovak abb. PRIdelenie VOzidiel Linkám = assignment of vehicles to lines) and this name is commonly used among the Czech and Slovak experts. Sometimes its meaning is a bit extended, and by PRIVOL not only the method is understood, but also the solved problem with the corresponding mathematical model.

\section{BASIC HYPOTHESIS}

The systems of urban transport lines have been optimized by PRIVOL in more than ten Czech or Slovak towns from 1988 up to now. However, it was in the "pure form" of P1/2 only seldom, e.g. in the Slovak town Pieštany in 2003. More often, the municipal managers requested some modifications of the method.

The main purpose of this Section is to present the basic hypothesis, to be proved in the Sections 3 and 4 . It is formulated as follows:

Basic Hypothesis: If the following specific practical requirements are individually incorporated into problems $\mathrm{P} 1$ or P2 then they can be formulated in linear form and solved by LP (= linear programming). The word "fleet" is a general expression for the rolling stock:

rq1) repetition of optimization with changed set $L_{0}$,

rq2) onesystem with heterogeneous fleet - vehicles with different number of places,

rq3) more than one system with homogeneous fleets,

rq4) heterogeneous fleet and heterogeneous groups of vehicles on lines,

ra5) increase disappointingly small percentage of direct travellers,

rq6) limited number of routes,

rq7) limited number of routes in several time periods,

rq8) elastic demand with respect to supply,

rq9) cost minimization in the case of one system with a homogeneous fleet,

rq10) cost minimization in the case of more than one system with homogeneous fleets,

rq11) more than one system with partially redundant fleet,

rq12) optimal use of partially redundant bus or trolleybus fleet in no mixed service,

rq13) optimal use of redundant bus fleet in mixed service,

rq14) optimal choice of representatives for groups of lines. 


\section{LESS KNOWN MODIFICATIONS OF PROBLEMS P1 AND P2}

In this Section, less known modifications are presented. Several of them, namely rq1, rq2, rq3 and rq5 were successfully used in practice, while rq2, rq3, rq4, rq5, rq6, rq7 and rq8 are mentioned in the conference presentation [11], but their presentation in Subsections 3.1-3.8 of the current paper is more complex due to increased practical experience of the authors. All eight cases show that these requirements are formulated in linear form and are solvable by LP, which confirms the validity of the basic hypothesis for rq1-rq8. New original modifications corresponding to rq9-rq14 requirements that have not yet been published or used in practice are described in Section 4.

\subsection{Increase of $y$ by repetition of optimization with changed set $L_{0}$ (rq1)}

When the method PRIVOL was applied in the Czech or Slovak towns, almost always the first resulting value $y$ was disappointingly small, much smaller than 1 , which signalized a small supply of places for passengers. Of course, such a solution was (and is) not feasible.

Since, usually, it is not possible to increase the vehicle fleet, it is necessary to look for the solution in routing. The way is to extend the candidate set $L_{0}$. For this purpose, a PC interactive "man-machine" program was prepared enabling the transport engineer

- to determine the "limiting" edges $e \in E$ where the left side of Constraint 4 is equal (or almost equal) to the right one,

- to design new lines, passing mainly through these edges, to be introduced into $L_{0}$.

Afterwards, a new calculation has been made with the changed set $L_{0}$. If the new resulting $y$ is not yet satisfactory, the procedures will be repeated, etc.

\subsection{One system with heterogeneous fleet - vehicles with different capacities (rq2)}

The following situation occurred many times in the past. In a town, there was bus transit, using vehicles with different number of places in operation. They were e.g. standard buses (with the "static" capacity of about 80 passengers, sitting or standing), midibuses (45 passengers), minibuses (25 passengers), or even articulated buses (140 passengers). In such a case, the definition of variables $x_{l}$, as the number of vehicles, lost any sense. The modification was that the meaning of $x_{l}$ was changed to dynamic capacity, i.e. the number of passenger places per hour on line $l$. Of course, it did not have to be an integer, but a non-negative real would have been sufficient.
Then neither Constraint 1 nor 4 could have remained unchanged. First of all, it was necessary to know total available capacity $c_{t o t}$ as the sum of capacities of all buses. Then Constraint 1 was replaced by

$$
\sum_{l \in L_{0}} \frac{t_{l}}{60} x_{l} \leq c_{t o t}
$$

Moreover, Constraint 4 got the form

$$
\sum_{l \in L 0: e \in E l} x_{l} \geq y f_{e} \text { for each } e \in E
$$

Hence, the modified version P2a is defined by 5,6 and 7 .

However, having dynamic capacities $x_{l}$ does not mean having the set of vehicles assigned to each line. For this purpose, a PC interactive "man-machine" program was prepared enabling the transport engineer to determine and to improve the assignment of vehicles to the lines i.e. to determine "realistic" values $x_{l}$ ' derived from the resulting $x_{l}$. The main goals of this procedure were

- not to abandon any line $l$ with, even small, $x_{l}>0$ if line $l$ is the only one passing through an edge $e$ with $f_{e}>0$ or if $x_{l} \geq b$ where $b$ is an upper bound of "negligible" values,

- to minimize differences $x_{l}-x_{l}^{\prime}$, especially when $x_{l}<x_{l}$.

Of course, if values $x_{l}$ are used instead of $x_{l}$ in Constraint 7 , there should exist $y \geq 1$ fulfilling it for each $e \in E$.

\subsection{More than one system with homogeneous fleets (rq3)}

Many Czech and Slovak towns have more than one system of surface public transport. One can see buses and trolleybuses. Very often, especially in the towns with about 100 thousand inhabitants, buses and trolleybuses are used (Zlín, Pardubice, Žilina, Prešov, etc.), some of such towns prefer buses and trams (Liberec, Olomouc). The larger towns have all three systems (Prague, Plzeň, Brno, Ostrava, Bratislava, Košice).

Then the following modification of problem P2 could be used, where $x_{l}$ means the number of vehicles.

First of all, if there were s systems, then set $L_{0}$ is split into parts $L_{01}, L_{02}, \ldots L_{0 s}$, where each $l \in L_{0 k}$ belongs to the $k$-th system, $k=1, \ldots, s$. Then, since it is assumed that all vehicles of the $k$-th system have equal capacity $c_{k}$, symbol $n_{k}$ denotes the number of available vehicles of the $k$-th system. Naturally, capacity $c_{l}$ of a vehicle assigned to a line $l \in L_{0 k}$ is $c_{l}=c_{k}$. Instead of Constraint 1 the following is used:

$$
\sum_{l \in L_{0 k}} x_{l} \leq n_{k} \text { for each } k=1, \ldots, s
$$

and, similarly,

$$
\sum_{l \in L: e \in E l} \frac{60 c_{l}}{t_{l}} x_{l} \geq y f_{e} \text { for each } e \in E
$$

Hence, the modified version is defined by 5,8 and 9 . 


\subsection{Heterogeneous fleet and groups of vehicles on lines (rq4) - exact solution}

Model 3.2 has been used in practice many times in cases when $k_{o}$ different types of vehicles with different static capacities $c_{k}$ (= numbers of places for passengers), $k=1, \ldots, k_{o}$ were available for operation. As a matter of fact, it is of a heuristic "man-machine" type and the same can be said if 3.3 is used for the solution of 3.2 as said in $5.3,3^{\text {rd }}$ paragraph. In both cases, the procedure is of a cascade type consisting of two steps. One of them is exactly calculated by a computer and the other is done "manually" by an engineer - in 3.2 it is the distribution of individual vehicles among lines and in the case of the use of 3.3 it is the "a priori" decision what size of vehicles is assigned to each line $l \in L_{0}$.

Now, in accordance to [11], a new approach can be proposed. It consists again of two steps, but both yield an exact solution.

The $1^{\text {st }}$ step is the same as in 3.2 i.e. by the solution of the problem defined by Constraints 5, 6 and 7 one reaches the dynamic capacities $x_{l}$ assigned to all $l \in L_{0}$. Then set $L$ of the selected lines $L=\left\{l \in L_{0}: x_{l}>0\right\}$. For the use in the $2^{\text {nd }}$ step $a_{l}=x_{l}$ for all $l \in L$ is denoted. Moreover, $n_{k}$ means the number of available vehicles of the $k^{\text {th }}$ type for $k=1, \ldots, k_{\text {o }}$.

$2^{\text {nd }}$ step: Define variable $z_{l k}$ as number of vehicles of the $k$-th type assigned to line $l$ for each $l \in L$. Find non-negative integers $z_{l k}, l \in L, k=1, \ldots, k_{o}$ and a real number $y$ ' such that

$$
\begin{aligned}
& \sum_{l \in L} z_{l k}=n_{k} \text { for each } k=1, \ldots, k_{o} \\
& \sum_{k=1, \ldots, k_{o}} c_{k} z_{l k} \geq a_{l} y^{\prime} \text { for each } l \in L \\
& y^{\prime} \rightarrow \max
\end{aligned}
$$

\subsection{Disappointingly small percentage of direct travellers (rq5)}

Managers of CS towns that have about one hundred thousand inhabitants asked the researchers to introduce a constraint concerning the percentage of direct travellers into the method PRIVOL. They usually wanted it above $90 \%$.

The solution was as follows. If the resulting number of direct travellers was under $90 \%$, then the reduced OD-matrix, remaining after the deletion of all directly travelling passengers, was denoted as $H=\left(h_{v w}\right)$. As usual, the set of the lines selected by PRIVOL was denoted $L$. Then such $l^{\prime} \in L_{0}-L$ was chosen that

$$
b \sum_{(v \in i)^{\wedge}(w \in i)} h_{v w}=\max _{l \in L 0-L}\left(\sum_{(v \in l)^{\wedge}(w \in l)} h_{v w}\right)
$$

and, for some "sufficient" $b>0$ the constraint

$x_{i} \geq b$

was added to the constraints of the problem and it was solved again. This step could be repeated until the percentage of direct travellers exceeded 90.

\subsection{Limited number of routes (rq6)}

It may happen that the public authority asks the transport engineers to keep the number of selected lines $|L|$ not exceeding the given limit $n^{*}$. The reason is that among CS transport engineers there is a widespread unwritten principle that the number of urban routes should not exceed the number $h p$ where $p$ is the population of the town and $h$ is a constant. The authors feel that it may be approximately $0.2 p$ if $p$ is expressed in thousands. For instance, if the population is 40,000 then the number of routes should not exceed 8.

If the basic form of PRIVOL (Problems P1/2) is to be used, then new binary variables $q_{l}$ for $l \in L$ are introduced where $q_{l}=1$ if $l$ is chosen to $L$ and $q_{l}=0$ otherwise. Then the following constraints should be added:

$q_{l} \leq x_{l} \leq 10^{6} q_{l}$ for each $l \in L_{0}$

$\sum_{l \in L_{0}} q_{l} \leq n^{*}$

\subsection{Limited number of routes in several time periods (rq7)}

It was not said explicitly, but it is obvious that, until now, all models have dealt with only one time period. Now, it is supposed that the route set optimization should be found by basic PRIVOL, i.e. analogically as in problems $\mathrm{P} 1$ or $\mathrm{P} 2$, for $g(>1)$ different time periods like morning peak and saddle, afternoon peak, evening, weekend, etc. It may happen that the optimal set of lines $L_{j}$ for the $j$-th period differs substantially from the others. The passengers do not like routes that pass different stops in different time periods to have the same number. However, there may be reasons for keeping the total number of lines under limit $n^{*}$. Of course, these lines may have different headways, i.e. different frequencies on the same routes (= sequences of stops) in different time periods. These requirements lead to the following problem formulation: to find a positive real number $y$ and non-negative integers $q_{l}$, (line $l$ choice indicator), $x_{l j}$ (number of vehicles on $l$ in the $j$-th period) for each $j=1, \ldots, g$ and $l \in L_{0}$ such that

$$
y \rightarrow \max
$$

$\sum_{l \in L 0} x_{l j} \leq n_{o j}$ for $j=1, \ldots, g$

$\sum_{l \in L 0: e \in E l} \frac{60 c}{t_{l}} x_{l} \geq f_{e j} y$ for each $e \in E$ and $j=1, \ldots, g$

$q l \leq \sum_{i=1}^{m} x_{l i} \leq 10^{6} q_{l}$ for each $l \in L_{0}$

$\sum_{l \in L_{0}} q_{l} \leq n^{*}$ 
where $n_{o j}$ is the given number of vehicles in service in the $j$-th time period and $f_{e j}$ is the given demanded number of places for passengers passing edge $e \in E$ in one direction in the $j$-th time period.

\subsection{Elastic demand with respect to supply ( $\mathrm{rq} 8)$}

This paragraph deals with a complex problem even for the basic PRIVOL, represented by problems P1 and $\mathrm{P} 2$. The reason is that the elasticity could be dependent on the place and time and be non-linear. In the sequel, only a simplified linear problem will be presented for problem P1.

Suppose that on each edge $e \in E$ the actual demand is $\varphi_{e}=f_{e}+b_{e} s_{e}$ where $s_{e}$ represents the supplied number of places for passengers passing through edge $e \in E$ in one direction, $b_{e}$ is a positive real number, $b_{e}<<1$ (i.e. $b_{e}$ is much smaller than 1 ) and $f_{e}$ is the original estimate of flow through $e$ derived from the O-D matrix. Then Constraint 2 turns to

$\sum_{l \in L 0: e \in E l} \frac{60 c}{t_{l}} x_{l} \geq \varphi_{e}=f_{e}+b_{e} \sum_{l \in L 0: e \in E l} \frac{60 c}{t_{l}} x_{l}$

which is equivalent with

$\left(1-b_{e}\right) \sum_{l \in L_{0}: e \in E_{l}} \frac{60 c}{t_{l}} x_{l} \geq f_{e}$ for each $e \in E$

\section{NEW ORIGINAL MODIFICATIONS OF PROBLEMS P1/P2}

The modifications presented here have not yet been published anywhere. Since requirements rq9-rq14 appeared only recently in the interviews of the authors with other experts, there is no experience with their application within the framework of PRIVOL in practice.

In all six cases it is shown that these requirements are formulated in linear form and solvable by LP, which confirms the validity of the basic hypothesis for rq9-rq14.

\subsection{Cost minimization in the case of one system with a homogeneous fleet (rq9)}

It may happen that passing of some edge $e \in E$ by public transport vehicles is considerably costly, e.g. there are many curves or the road goes up and down or there is a necessity for braking and accelerating many times, etc. Then it is welcome if the supply of places of passengers per hour does not redundantly exceed demand $f_{e}$. It is then possible to use the following modification of the basic Problem P1: Let $y_{o}>0$ be a given constant, representing the lower bound of admissible supply/demand ratio. Let $\gamma_{e}>0$ be the cost of one passing through edge $e \in E$ by a unique vehicle. Let the other denotations be the same as in the case of Problem P1. Then the modified problem is to find the number of vehicles $x_{l}$ assigned to line $l$ for each $l \in L_{0}$ meeting Constraints 1, 24 and 25 .

$\sum_{l \in L 0: e \in E l} \frac{60 c}{t_{l}} x_{l} \geq y_{o} f_{e}$ for each $e \in E$

$\sum_{e \in E} \sum_{l \in L 0: e \in E l} \frac{60 c}{t_{l}} \gamma_{e} \chi_{l} \rightarrow \min$

\subsection{Cost minimization for more than one system with homogeneous fleets (rq10)}

The situation, motivation of problem solving and its goals are almost the same as in 4.1 The only difference is that instead of one system there are $s$ different systems here. Hence, set $L_{0}$ is split into parts $L_{01}, L_{02}, \ldots L_{0 s}$, where each $l \in L_{0 k}$ belongs to the $k$-th system. All vehicles of the $k$-th system had equal capacity $c_{k}$ and the symbol $n_{k}$ denotes the number of available vehicles of the $k$-th system. Consequently, capacity $c_{l}$ of a vehicle assigned to a line $l \in L_{0 k}$ is $c_{l}=c_{k}$. Moreover, $\gamma_{e k}>0$ denotes the cost of one passing through edge $e \in E$ by a unique vehicle of the $k$-th system. The problem is then to find the number of vehicles $x_{l}$ assigned to line $l$ for each $l \in L_{0}$ meeting Constraints 8,24 and 26 .

$$
\sum_{k=1}^{s} \sum_{e \in E} \sum_{l \in L 0 k: e \in E_{l}} \frac{60}{t_{l}} \gamma_{e k} x_{l} \rightarrow \min
$$

\subsection{More than one system with partially redundant fleet}

Suppose that the modification 3.3 of Problem P2 has been resolved with the resulting value $y$. For some $k \in\{1, \ldots, s\}$ it has been found that the same resulting value $y$ is reached even if $n_{k}$ was replaced by $n_{k}-1$. This indicates that one vehicle of the $k$-th system is redundant and its use may cause inutile costs. With subsequent repeating of such a stepwise reduction one can reach such an $s$-tuple $n_{1}-d_{1}, \ldots, n_{s}-d_{s}$ that none of its elements can be reduced without the reduction of value $y$. Of course, such an $s$-tuple need not be unique; different ordering of indices $k$ may lead to different final $n$-tuples.

However, this problem can be conceived in another way. Suppose that a (fixed) cost $\gamma_{k}$ is given for one vehicle use of each $k=1, \ldots, s$ and the other denotations are the same as in 3.3 (Constraints 8 and 9). Value $y$ is given like several rows above. Then the problem is to find the integers $x_{l}$ for $l \in L_{0}$ such that

$$
\sum_{k=1}^{s} \gamma_{k} \sum_{l \in L 0 k} \chi_{l} \rightarrow \min
$$

\subsection{Optimal use of partially redundant bus or trolleybus fleet - no mixed service}

No mixed service means that it is not allowed to use a bus on trolleybus lines. Suppose that the available numbers of buses and trolleybuses are $n_{1}$ and $n_{2}$, 
respectively. Suppose further that for the given $n_{1}, n_{2}$, the solution of problems 3.3 and 4.3 has been already done with the resulting values $y_{o}$ and $x_{o l}, l \in L_{0}$. Denote $E_{k}$ set of all edges, belonging to any $l \in L_{0 k}, k=1,2$. Denote

$n_{k}^{\prime}=\sum_{l \in L_{0 k}} \chi_{o l}$ for $k=1,2$

i.e. $n_{k}^{\prime}$ is the number of vehicles from the $k$-th system that are necessary for reaching value $y_{o}$. Value $\delta_{k}=n_{k}-n_{k}^{\prime}$ represents the number of "free" vehicles that can be used for the improvement of passenger comfort on the edges passed by the lines of the $k$-th system. If the fleet is partially redundant, then at least one of these differences is positive. Suppose it is the $h$-th system where $\delta_{h}>0$. The problem is to find a real value $y>y_{o}$ and non-negative integers $x_{l}, l \in L_{0}$ meeting Constraints 5, 8, 29 and 30 .

$$
\begin{aligned}
& \sum_{l \in L 0: e \in E 1-h} \frac{60 c_{l}}{t_{l}} x_{l} \geq y_{o} f_{e} \text { for each } e \in E_{1-h} \\
& \sum_{l \in L 0: e \in E h} \frac{60 c_{l}}{t_{l}} x_{l} \geq y f_{e} \text { for each } e \in E_{h}
\end{aligned}
$$

If the resulting $y>y_{o}$, then the comfort of passengers, using only the $h$-th system, increases using the whole fleet of $n$ vehicles, compared with the case when only $n_{1}^{\prime}+n_{2}^{\prime}$ was used and the comfort of the others did not decrease.

\subsection{Optimal use of redundant bus fleet in mixed service}

In contrast to the previous Section, mixed bus-trolleybus traffic is allowed on the trolleybus lines. The denotations are the same as in 4.4. Similarly, it is assumed that, for the given $n_{1}, n_{2}$, the solution of problems 3.3 and 4.3 has been already done with the resulting values $y_{o}$ and $x_{o l}, l \in L_{0}$. Of course, $h=1, \delta_{1}>$ 0 since the mixed traffic has sense only if the bus fleet is redundant.

The problem is to find a real value $y$ and non-negative integers $x_{l}, l \in L_{0}$ meeting Constraints 5, 9, 31 and 32.

$$
\begin{aligned}
& \sum_{l \in L_{01}} x_{l} \leq n_{1} \\
& \sum_{l \in L_{02}} x_{l} \leq n_{1}+n_{2}
\end{aligned}
$$

\subsection{Groups of lines - optimal choice of representatives}

It happens that the basic set of lines $L_{0}$ is split into groups $L_{00}, L_{01}, \ldots, L_{0 k}$ and the problem is to choose exactly one representative line from each group $L_{01}, \ldots, L_{0 k}$ and arbitrary (even empty) subset of lines from $L_{00}$ into the resulting set $L$. For instance, it may be caused by the fact that each group $L_{01}, \ldots, L_{0 k}$ corresponds to a non-negligible but weak flow of passengers.
The corresponding modification of Problem P2 is the following: find non-negative integers $x_{l}, l \in L_{0}$ meeting Constraints 1, 4, 5 and 33.

$\sum_{l \in L k} x_{l}=1$ for $k=1, \ldots, n$

\section{DISCUSSION}

\subsection{Discussion to Section 1}

Comment to merging of routing and frequencing (see Section 1 after the list of planning steps). Of course, it is not necessary to do these two steps at the same time in one unique procedure. First, do the $2^{\text {nd }}$ step, e.g. by genetic algorithm as in [12] and afterwards the $3^{\text {rd }}$ one, e.g. by "classic" procedures from [13]. However, many practitioners prefer, in general, the merged steps on which the current paper is focused.

Response on small changes in demand, candidate network or fleet (see Section 1). Naturally, it may happen that after some time (months or years), passenger demand, available "candidate" network or available fleet slightly change and the current routing and frequencing remains optimal no longer. Then, it will not be necessary to look for a completely new solution but it will be sufficient to modify the existing solution, as described e. g. in [14, 15 or 16]. It is possible to do this using PRIVOL as well, but not in the exactly optimal manner. Moreover, it is not certain that, comparing with [16], such a high percentage of the existing lines remains intact. Using PRIVOL in this case requires sensitive changes of the initial "candidate" set of routes $L_{0}$

Comment to one-level approach. In the current paper, the one-level approach is adopted in the formulations of the line creation problems to be solved. Here, an a priori distinction of "levels" is not included, i. e. specific types of service designed to serve particular markets like in [17] for Zurich in Switzerland. Neither are there distinguished public transport subsystems of "higher" and "lower" levels. If they are expected in practice, the current paper assumes first to deal with the lower level alone and, if necessary, to create the lines of the higher level separately afterwards. For instance, if feeder lines are required for connecting the lower level with the higher one, as in [18], then these passengers are considered in the O-D matrix similarly as other passengers demanding transport in the lower level only.

Note on the candidate set of routes $L_{0}$ (see Section 1, paragraph Erlander Approach). In practice, in most cases, set $L_{0}$ is constructed by traffic engineers "manually", using their erudition and experience. However, as shown e.g. in [19, 20, 21 and 22], creation of new 
lines is possible also in a "scientific" manner, using mathematical models and methods together with a solution on a computer.

Note on the constancy of the cycle time and on the stationarity of the set of lines (see Section 1, paragraph Erlander Approach). Value $t_{l}$ is supposed to be constant. However, this assumption may be considered acceptable only for some periods like morning and af ternoon peak, morning and evening saddle, (both on workdays), Saturday morning, etc. Therefore, applying the Erlander approach in line creation for each individual period, the frequencies on the selected routes may be (naturally) different. It can even happen that the set of operated routes in one period is not identical with the set in the other one. For example, in the Slovak town Žilina, after the line optimization in 1989, there was a "saddle" line, having the route partially (about one third) different from the "peak" sister. Or, in Linköping (Sweden) at about the same time, there was an "evening saddle" bus line connecting suburban residential areas without passing through the city centre. Of course, such a line would not have any sense in the peak hours.

A bit different approach can be found in [23] where the running times (including $t_{l}$ ) are a priori considered random.

Note to periodicity of timetables. Public administration officers have very different ideas about whether and in what sense public transport timetables should be periodic. Some do not require them at all, others only for a few key lines and some for all of them. Some of them accept only constant headways (in minutes) from the integer divisors of $60: D(60)=\{60,30,20,15$, $12,10,6,5,4,3,2,1\}$, Some of them, e. g. in Žilina in the nineties, accepted also $7.5 \mathrm{~min}$ (in driver's schedule and alternations $7,8,7,8$ in public timetables). In Olomouc in the nineties the authors were told that the officer accepted only the configuration $4,4,4,4$,.. of headways in rush hours on one main street, while, on two other similar main streets, they accepted also the less regular configuration $5,3,5,3, \ldots$

Mainly (but not only) in off-peak periods, unnecessarily long idle time in terminals may be caused by the inconsistency of cycle time $t$, with the requirement of periodicity. For instance, in Pardubice in the nineties, the computer was forced to choose a route $l$ with $t_{l}=62$ and the expected headway of 15 or 20 min into set $L$, with consequent inutile additional idle time 13 or $18 \mathrm{~min}$ in the new extended cycle of the length of 75 or $80 \mathrm{~min}$, i.e. $17 \%$ or $23 \%$ of the total working time. It is difficult to find any universal approach to this issue. However, in order to avoid such issues, it is possible to formulate the following general advice based on the authors' long experience: Keep in mind the requirements of periodicity in the design phase of the set of candidate routes $L_{0}$ !
A good example was in Žilina, when all the candidates for the role of the key lines with saddle headways about 10 or 15 minutes, had the saddle value of $t_{l}$ just under 60 or 90 minutes, such as 59,58 , or 88 , 90 with the necessity of only small additional idle time 0,1 or 2 min in terminals when $l$ was chosen to set $L$.

\subsection{Discussion to Section 2}

Note on the completeness of the list of requirements. This list includes all the requirements that the authors encountered in interviews with the Czech and Slovak public transport managers during the last years. It does not, however, include all the criteria applied in the creation of lines in the world literature - see, for example, aspects of emissions, noise and accidents on the selected routes in [24] or capacity issues in [6].

\subsection{Discussion to Section 3}

Increase of " $y$ " by repetition of optimization with changed Set $L_{0}$ (see 3.1). When the method PRIVOL was applied in the Moravian town Olomouc in the nineties, the first round led to the value $y \approx 0.5$, i.e., the demand was double supply. After five repetitions of calculations with subsequently augmented set $L_{0}$ of candidate routes, value $y>1$ was reached.

Note to vehicles with different number of places (see 3.2). In Žilina in 1989 the fleet consisted of standard buses for 90 passengers and articulated ones for 145 passengers. The authors worked with the candidate set $L_{0}$ so carefully that in the rush hours, after the optimization as in problem $\mathrm{P} 2$ with resulting $x_{l}, l \in L$, all the key lines had a unique headway of 5 min and each such line had assigned buses of only one size.

Note to different systems (see 3.3). This model can be used also in the case of 3.2, mainly when it is possible, in advance, to assign a single size of vehicle to each line $l$ following e.g. some transport engineering aspects (necessity of a small vehicle because of sharp turns on the route etc.). Then the problem turns into the one presented in 3.3.

If there is more than one system and some of them use heterogeneous (with respect to capacity) fleet, then such a system can be split into subsystems with homogeneous fleets assuming that each line is a priori assigned to some subsystem. Then the problems 8, 9 and 5 can be applied as well.

A small pitfall in the case of 3.3. The authors met an interesting situation in Pardubice in the late nineties. There were two systems, buses and trolleybuses. The bus fleet was homogeneous from the point of vehicle capacity - each bus had about 90 places for passengers (sitting and standing together) and almost the same could be said about trolleybuses; each had a capacity of about 82. Coincidentally, the number of buses available was 40 , the same as for trolleybuses, i.e. $n_{1}=n_{2}=40$ in the model. After several rounds of type 
3.1 a solution with $y>1$ was obtained. When the number of buses was changed to $n_{1}=39$, then the resulting $y$ worsened under the previous value. On the contrary, if the number of trolleybuses was reduced from 40 to $n_{2}=39$, the resulting $y>1$ remained unchanged, similarly as for $n_{2}=38,37, \ldots$, until 27 . Only value $n_{2}=26$ caused worsening of $y$ under the previous value. Hence, 13 trolleybuses seemed "inutile" from the point of view of the global value of $y$. It was another managerial decision problem to be solved. However, a similar approach to the one described in 4.4 or 4.5 , had not been known yet at that time. Hence, the competent managers preferred another solution - the electrification of other streets, allowing a new trolleybus line to be added (mainly the today's trolleybus line No. 13 with $5 \mathrm{~min}$. headway in the peak). That balanced the "demand" for buses with the one for trolleybuses.

Comment to 3.4. The number $a_{l}$ represents the "ideal" capacity of line $l$, and the numbers of vehicles $z_{l k}$ represent the final result for the service. Constraint 11 ensures that the relative satisfaction of line $l$ is at least $y$ ' and 12 ensures that it is the maximum possible.

Note to exactness of the solution from 3.5. This procedure is of the 'greedy' heuristics type, i.e. it is not able to guarantee optimality of the solution. Dr Tomáš Majer from the University of Žilina informed the authors that he elaborated an exact "one-step" model based on integer LP that surely leads to the optimum. The publication was expected in 2018.

Remark to 3.5. The expression "sufficient" $b>0$ in 14 means "such a $b>0$ that provides sufficient capacity for the transportation of at least the abovementioned number $h^{*}$ of passengers on line $l$ '. It depends on mutual overlapping of parts used by $h_{v w}$ passengers for $v \in l^{\prime}, w \in l^{\prime}$.

Note to the choice of values $n_{o j}$ in 3.7. At the beginning, number $n_{o j}$ vehicles in service in the $j$-th period is chosen $n_{o j}=n$ (= the size of the available fleet) for each $j=1, \ldots, g$. Assume that it leads to value $y$ of the minimal relative excess of supply over demand. Then, similarly as in 4.3, there exists a (not unique) $g$-tuple $n_{o 1}, \ldots, n_{o g}$ such that $n_{o j}=n-d_{j}$ for $j=1, \ldots, g$ leads to the same value $y$ but any replacing of $d_{j}$ by $d_{j}+1$ decreases value $y$. These numbers of vehicles $n_{o 1}, \ldots, n_{o g}$ can be used for different periods.

Note to 3.8. This type of demand elasticity assumes that there is a "basic" demand $f_{e}$ on each $e \in E$ and, moreover, when the supply of posts of passengers is $s_{e}$ then there will be an increase in demand that is linearly dependent on $s_{e}$ with a coefficient $b_{e}$. Since Constraint 2 requires that the supply is not lower than the demand, which increases with the supply now, Constraint 2 is replaced by 22, transformed to 23 . Actually, it is a linear approximation of non-linear dependency of demand on supply (the total number of inhabitants is a natural limit, not allowing unlimited linear increase of passenger demand).

\subsection{Discussion to Section 4}

Note on the relationship of values $y_{o}$ and $y, \delta_{1}$ and $\delta_{2}$.in 4.4 and 4.5 . Imagine a town situated in a narrow valley on both banks of the river. A single road with one bus line, parallel to the river, runs along each bank. Both lines are equally long, they have the same demand of passengers, they run the same buses at the same headways of 15 minutes, and three vehicles on each line. Assume that the minimum $y_{o}$ is reached on both lines and that, afterwards, there is one vehicle added to the system. Whether it is assigned to any line, the minimum value $y_{o}$ for the entire system remains unchanged.

Assume another town in a wider valley with four parallel equally long lines with equal demands of passengers, equal headways of equally capacitated vehicles, three buses on each of the first two lines and three trolleybuses on each remaining line. Let minimum $y_{o}$ be reached on each of the four lines and, afterwards, one bus and one trolleybus are added to the fleet. Then $y_{o}$ remains unchanged and it is reached in both bus and trolleybus systems. After applying $4.4, \delta_{1}=\delta_{2}=1$ the maximum $y$ remains $y_{o}$ both for buses and trolleybuses.

On the other hand, if the redundant bus is added to the trolleybus fleet, then for the entire system the resulting $y$ remains unchanged $y=y_{o}$, but the trolleybus subsystem reaches $y=1.25 y_{0}$.

\subsection{General discussion}

PRIVOL - tool for urban or rural transport? This is a frequently but incorrectly asked question, since PRIVOL is a tool for the line design, when the passenger demand is expressed in the form of passenger flows and the corresponding supply is expected in the form of vehicle flow, or the related headway. Therefore, this is encountered much more often in urban transport than in the rural areas (in the Czech and Slovak Republics PRIVOL was used in urban cases only).

Benefits for the main stakeholders in urban transport. The most important stakeholders are passengers. Among others one has to emphasize the carriers (usually a city transport company) and municipal authorities. Almost always the latter ones are donors, i.e. subsidizing institutions for the carriers that have more operating costs than incomes from fares and advertisements.

After PRIVOL is applied, the main benefit to passengers are the travel time savings due to more straightforward line routes and smaller headways, although it sometimes happens that the walking distance to the nearest stop is slightly greater. The main benefit to donors are cost savings with unchanged incomes and transport quality. For instance. in the Slovak town Žilina (population about 100,000 ) in 1989 , about $7 \%$ of 
vehicle kilometres were saved. For more recent applications, it is difficult to obtain data on specific savings that are considered to be "business secrets".

\section{CONCLUSION}

The paper deals with urban transport line planning, in two directions. First, two original objectives, not yet mentioned in the survey type papers like [6] or [7], are described:

1) The number of vehicles in service (to be minimized), provided all passengers are transported at the acceptable degree of comfort. Comfort is expressed by the relative excess of passenger places supply over demand.

2) The minimum relative excess of supply over demand (to be maximized) without exceeding the number of available vehicles.

These two objectives were used in the formulation of two problems, P1 and P2. Mathematical models for both problems are presented and the possibilities of solution outlined.

The second and the main direction of the current paper is to describe fourteen modifications rq1-rq14 of problem P2 and to outline their practical applications.

Thus, it can be said that the paper brings three benefits to the reader:

- it introduces them to PRIVOL - a successful Czech-Slovak method of designing public transport lines, based on MILP, which has not yet been reported by any international survey paper,

- for the first time in a scientific journal, it presents eight specific practical requirements and shows how they can be expressed linearly and be included in PRIVOL (so far only described in the proceedings of a Czech-Slovak scientific conference),

- as an original contribution to the development of transport science, it introduces six new modifications of the PRIVOL method, enabling the resolution of six unresolved practical decision-making problems.

As concerns the benefits to the main stakeholders after applying PRIVOL, the paper shows that the main benefit to passengers are travel time savings due to more straightforward line routes and smaller headways, while the main benefit to providers are smaller costs (e.g. due to vehicle kilometres savings) maintaining the incomes and the travel quality unchanged.

The future research can be expected mainly on the following issues:

- elastic demand with respect to supply - the extension of model 3.8 to a non-linear elasticity function;

- extension of 4.4 and 4.5 to the case of more than two systems;

- incorporation of operation costs into 3.4, 4.4, 4.6 and, maybe, into some others as well,
- (in the more distant future) incorporation of rebuilding costs or health threatening costs (emissions, noise etc.) of candidate sections into the common solution of routing and frequencing by linear programming.

\section{ACKNOWLEDGEMENT}

This paper was prepared with the support of the Project No. IP 600040, Faculty of Management, University of Economics, Prague and the Slovak research grants VEGA 1/0582/16 Economic optimization of networks processes, VEGA 1/0342/18 Optimal dimensioning of service systems and APVV-14-0658 Optimization of urban and regional public personal transport".

\section{JAN ČERNÝ ${ }^{1}$}

E-mail: cerny@fm.vse.cz

ŠTEFAN PEŠKO ${ }^{2}$

E-mail: pesko@ frcatel.fri.uniza.sk

ANNA ČERNÁ ${ }^{1}$

E-mail: cerna@fm.vse.cz

${ }^{1}$ Fakulta managementu

Vysoká škola ekonomická v Praze

Jarošovská 1117/II, 37701 Jindřichův Hradec,

Česká republika

${ }^{2}$ Fakulta riadenia a informatiky

Žilinská univerzita

Univerzitná 1, 01026 Žilina, Slovakia

\section{ALTERNATÍVNE KRITÉRIÁ, POUŽÍVANÉ PRI PLÁNOVANII LINIEK VEREJNEJ DOPRAVY POMOCOU LINEÁRNEHO PROGRAMOVANIA}

\section{ABSTRAKT}

Plánovaním liniek verejnej dopravy sa v článku rozumie navrhovanie ich trás a frekvencie spojov na nich. Vo svetovej literatúre sa $v$ tejto súvislosti zvyčajne používajú rôzne kritériá, najmä variabilné náklady liniek, fixné náklady liniek, súčet týchto nákladov, počet cestujúcich bez prestupovania, celkový lebo priemerný čas cestovania, prípadne celkový lebo priemerný čas prepravy. Článok pridáva dve d'alšie, a to celkový počet použitých vozidiel (minimalizuje sa pri podmienke, že sa všetci dopytujúci cestujúci prepravia) a pomerný previs ponuky miest nad dopytom (maximalizuje sa pri podmienke neprekročenia počtu disponibilných vozidiel). Pre obidva prípady sa uvádzajú matematické modely, spolu s motiváciou takéhoto prístupu a stručným pohl'adom do histórie českého a slovenského výskumu tejto problematiky. Základné modely sa d'alej modifikujú pre rôzne špeciálne požiadavky z praxe (napr. heterogénny park vozidiel, obmedzenie počtu prestupov, elastický dopyt, ohraničenie celkového počtu liniek apod.). Napokon sa uvádza krátky popis skúseností s praktickým využitím týchto postupov.

\section{KL'ÚČOVÉ SLOVÁ}

verejná doprava; plánovanie liniek; lineárne programovanie; kritérium; účelová funkcia; 


\section{REFERENCES}

[1] Ceder A. Public Transit Planning and Operation: Theory, Modeling and Practice. Oxford, UK: Elsevier, Butterworth-Heinemann; 2007.

[2] Desaulniers G, Hickman MD. Public transit. In: Barnhart C, Laporte G, editors. Handbook in Operation Research and Management Science: Transportation. Vol. 14. Amsterdam: Elsevier; 2007. p. 69-127.

[3] Guihaire V, Hao JK. Transit network design and scheduling: A global review. Transportation Research Part A. 2008;42(10): 1251-1273.

[4] Ibarra-Rojas OJ, Delgado F, Giesen R, Muñoz JC. Planning, operation, and control of bus transport systems: A literature review. Transportation Research Part $B$. 2015;77: 38-75.

[5] Chua TA. The planning of urban bus routes and frequencies: A survey. Transportation. 1984;12(2): 147-172.

[6] Kepaptsoglou K, Karlaftis MG. Transit Route Network Design Problem: Review. Journal of Transportation Engineering. 2009;135(8): 491-505.

[7] Schöbel A. Line planning in public transportation: models and methods. OR Spectrum. 2012;34(3): 491-510.

[8] Erlander S, Schéele S. A Mathematical Programming Model for Bus Traffic in a Network. Proceedings of the $6^{\text {th }}$ International Symposium Transportation and Traffic Theory, Vol VI, 1974 August 26-28, Sydney, Australia.

[9] Černý J, Černá A. Erlander Principle in Managerial Decision Making on Czech and Slovak Urban Transport Routes. E\&M Economics and Management. 2013;16(1): 93-100.

[10] Daněk J, Plevný M, Teichmann D. The Rational Operation of the Urban Transport Line Network by Minimisation of the Needed Vehicles. Ekonomie a management. 2010;13(2): 53-61.

[11] [11] Černá A, Černý J, Peško Š. Modification of the Method PRIVOL for Optimal Routing and Frequencing. Proceedings of the $32^{\text {nd }}$ International Conference on Mathematical Methods in Economics, 2014 September 10-12, Olomouc, Czech Republic. p. 89-94.

[12] Bielli M, Caramia M, Carotenuto P. Genetic algorithms in bus network optimization. Transportation Research Part C. 2002;10(1): 19-34.

[13] Furth PG, Wilson NHM. Setting frequencies on bus routes: Theory and practice. Transportation Research Record. 1982;818: 1-7.

[14] Matisziw TC, Murray AT, Kim C. Strategic route extension in transit networks. European Journal of Operational Research. 2006;171(2): 661-673.

[15] Szeto WY, Jiang Y. A hybrid artificial bee colony algorithm for transit network design. Transportation Research Record. 2012;2284: 47-56.

[16] Mahdi Amiripour SM, Mohaymany AS, Ceder A. Optimal modification of urban bus network routes using a genetic algorithm. Journal of Transportation Engineering. 2015;141(3): Article No. 04014081.

[17] Orth H, Nash A, Weidmann U. Level-based approach to public transport network planning. Transportation Research Record. 2015;2537: 1-12.

[18] Chien S, Schonfeld P. Joint optimization of a rail transit line and its feeder bus system. Journal of Advanced Transportation.1998;32(3): 253-284.

[19] Chen J, Wang S, Liu Z, Wang W. Design of suburban bus route for airport access. Transportmetrica A: Transport Science. 2017;13(6): 568-589.

[20] Kuah GK, Perl J. Optimization of feeder bus routes and bus-stop spacing. Journal of Transportation Engineering. 1988;114(3): 341-354.

[21] Wang S, Qu X. Rural bus route design problem: Model development and case studies. KSCE Journal of Civil Engineering. 2015;19(6): 1892-1896.

[22] Pribyl V. Solution of the bus route design problem. Communications. 2009;13(3): 25-28.

[23] Yan Y, Liu Z, Meng Q, Jiang Y. Robust optimization model of bus transit network design with stochastic travel time. Journal of Transportation Engineering. 2013;139(6): 625-634.

[24] Jiang Y, Szeto WY. Time-dependent transportation network design that considers health cost. Transportmetrica A: Transport Science. 2015;11(1): 74-101. 